\title{
Hacia una psicopolítica del mercado. El neuromarketing
}

Towards a psycho-politics of the market. Neuromarketing

Rita-María Pérez-Pérez

Universidad del País Vasco (UPV/EHU)

ritamariaperezperez@yahoo.es

\section{Forma de citar este artículo:}

Pérez-Pérez, R. M. (2019). "Hacia una psicopolítica del mercado. El neuromarketing", RAEIC, Revista de la Asociación Española de Investigación de la Comunicación, vol 6, núm. 11, 46-67. DOI: https://doi.org/10.24137/raeic.6.11.4

\section{Resumen:}

Este trabajo tiene como objetivo principal determinar en qué medida el aporte científico ha abierto la posibilidad de aplicar estrategias publicitarias novedosas y positivas para el crecimiento del mercado. Presta especial atención a los estudios del neuromarketing y analiza que el desarrollo de la publicidad se produce de forma paralela a la masificación del consumo, a la competencia del mercado y al crecimiento de la riqueza en los diferentes países, pues -en la medida en que disminuyen las necesidades de los consumidores - la publicidad tiene que crear necesidades nuevas y para ello precisa de la investigación científica que, ante las demandas actuales, desemboca en el neuromarketing.

Palabras clave: publicidad, consumo, emociones, investigación, neuromarketing. 


\section{Abstract:}

The main objective of this work is to determine to what extent the scientific contribution has opened the possibility of applying novel and positive advertising strategies for the growth of the market, paying special attention to neuromarketing studies. This research analyzes that the development of advertising occurs in parallel to the mass consumption, market competition and the growth of wealth in developed countries, because - to the extent that wealth increases and the needs of the consumers decrease- advertising has to stimulate these needs by creating new ones, for which it requires scientific research that, in the face of current demands, leads to neuromarketing.

Keywords: advertising, consumption, emotions, investigation, neuromarketing.

\section{INTRODUCCIÓN}

La publicidad moderna se inicia hacia finales del siglo XIX en los Estados Unidos, pero se hace vigorosa en el transcurso del siglo XX cuando los profesionales de la comunicación publicitaria -preocupados por estudiar a los consumidores, sus conductas e intereses personales en relación con los productos- realizan investigaciones para conocer los mecanismos más fiables y prácticos para hacer más efectiva la comunicación con los clientes-objetivo. De este modo, poco a poco, se implantan estrategias innovadoras cuyo éxito se ve reflejado en la subida de las ventas. Sin embargo, a medida que avanza la sociedad, se desarrolla la tecnología y progresa la globalización, la eficacia de estas herramientas disminuye y la mercadotecnia necesita buscar nuevos mecanismos para mejorar el consumo. Sobre esta base, nuestra investigación se propone determinar en qué medida el aporte científico contribuye a la eficacia de la comunicación publicitaria, y presta especial atención a los estudios de neuromarketing.

\section{METODOLOGÍA}

El presente trabajo es el resultado de una amplia revisión bibliografía sobre la cuestión objeto estudio. Ello nos ha revelado la importancia de la investigación científica aplicada a la publicidad, no sólo porque permite descubrir herramientas publicitarias novedosas 
y positivas para el crecimiento del mercado, sino porque advierte y previene sobre su comportamiento futuro y sobre los cambios que se generan para sustituir, mantener o buscar nuevos mecanismos que mantengan o acrecienten la demanda. Esta realidad hoy desemboca en las neurociencias y, de manera específica, en la aplicación de estrategias provenientes del neuromarketing.

Para la investigación hemos utilizado una metodología cualitativa a través de la recopilación de información procedente de diversas fuentes bibliográficas relacionadas con el tema objeto de estudio de este trabajo.

\section{LA INVESTIGACIÓN CIENTÍFICA PARA EL ÉXITO PUBLICITARIO}

El desarrollo de la publicidad en el siglo XX está unido indisolublemente a la investigación científica. El exceso de producción que se produjo en la década del cincuenta de la pasada centuria supuso una amenaza para el capitalismo y los empresarios para evitar otra depresión económica se vieron en la necesidad de buscar alternativas que incentivaran la demanda. "En las conferencias de dirigentes se hablaba de 'revolución del mercado', y se reflexionaba mucho sobre los medios para 'estimular' a los compradores creando en ellos necesidades cuya existencia ignoraban" (Packard, 1957, p. 43). A modo de ejemplo, Packard (1957, p. 46) refiere que un columnista publicitario del New York World-Telegram and Sun, comentaba el hecho de que los vendedores estaban "buscando vías para precondicionar al cliente para comprar sus productos grabando las características del producto en su cerebro". Entonces, los publicitarios comenzaron a hablar sobre los niveles de la conciencia humana: El primero, la conciencia o nivel racional, en el que las personas saben lo que hacen y son capaces de decir por qué. El segundo, la preconciencia o subconsciente, que corresponde a ese nivel en que una persona sabe de manera vaga lo que hace, pero no es capaz de decir por qué. $Y$ el tercero, el inconsciente o nivel en que las personas no son conscientes de sus actitudes ni de sentimientos y, además, no discutirían acerca de ellos si pudieran. Según Packard (1957, p. 47), "la exploración de nuestras actitudes con respecto a los productos, en esos segundo y tercer niveles, es ahora conocida como la nueva ciencia del análisis o investigación motivacional [motivational analysis or research]". 
Russell, Tomás et al (2005, p. 5-6) explica que,

(...) al crear la producción en masa una sobreabundancia de productos y marcas competidoras, la publicidad no debe solamente informar y persuadir a los consumidores potenciales que estos productos existen, sino también dar a los consumidores razones para comprar una marca o categoría de productos en vez de aquéllos de los competidores.

Para esta época, la publicidad comenzaba a ver los frutos de las investigaciones de las ciencias sociales encaminadas a hacer más efectiva la comunicación con los consumidores. Rothenberg (1999, p. 12) expresaba:

Si las ventas no dependieran no de los precios cada vez menores no de las mejoras tecnológicas reales, sino de las percepciones de status, necesidades artificiales y cambio superficial, entonces enfocarse en la marca en vez de en productos individuales podría ser la mejor manera para que un vendedor lograra rentabilidad duradera. Después de todo, los productos tienen ciclos de vida y mueren. Una marca bien manejada podría durar para siempre.

Sobre la base del trabajo de Watson y otros autores, Alfred Sloan, Jr. desarrolló la idea de que el automóvil era un símbolo de estatus social y convirtió la General Motors (GM) en la industria más valiosa de fabricación de autos. Los fabricantes se habían percatado del importante significado que la apariencia externa podía tener para el crecimiento de la demanda (Lipovetsky, 1990, p. 185). De esta manera, para los años 1950 y 1960 la mayoría de las empresas habían hecho suyo el concepto de que sería la marca la que establecería el éxito o el fracaso de las compañías y no la superioridad real de la mercancía (Rothenberg, 1999, p. 12).

Estados Unidos, Alemania y Reino Unido son países en los que la investigación científica aplicada a la publicidad ha alcanzado un amplio desarrollo y hoy goza de gran reputación. En Estados Unidos, particularmente, esto se explica porque "fue la cuna de la publicidad como profesión y también de los primeros libros técnicos y revistas profesionales a finales del siglo XIX" (Correyero, Machado y Baladrón, 2018). Las 
investigaciones de mercado se originan, vinculadas a las encuestas a pie de calle, para conocer la eficacia de la publicidad. Sin embargo, adquieren tal reputación durante las cuatro primeras décadas del siglo XX que se popularizan y se utilizan en diferentes disciplinas científicas para atender las demandas del gran público. A pesar de ello, faltaba conocer a los consumidores a nivel individual sus motivaciones, emociones, deseos y actitudes. Entonces, entre los años 40 y 60 se introducen las investigaciones cualitativas con herramientas "como los focus group, las entrevistas en profundidad y también las técnicas de observación” (López, 2017, p. 6), cuya información contribuyó a la eficacia de las estrategias de mercado.

Sergio Zyman (1999, p. 62) explica que la investigación revierte amplios beneficios a la rentabilidad de las empresas "porque cuando entiendes el porqué, es mucho más sencillo entender cómo producir lo que quieres". Con una óptica parecida, Bassat (1998, p. 51) considera que la investigación científica es indispensable para la efectividad de los mensajes, ya que la tarea del publicista es: "1. Despertar un deseo o pasión utilizando aquellas tendencias que nos pueden llevar más lejos en nuestras intenciones. [Y] 2. Convencer de que este deseo sólo puede saciarse con la posesión del objeto que anunciamos". La persuasión publicitaria debe orientarse a buscar la "estrategia que impulse al máximo las motivaciones, basándonos en el producto, la propia estima y la imagen social". En otras palabras, actuar para que la racionalidad del cerebro no frene los impulsos emocionales.

Ogilvy habla de tres tipos de ventajas para incentivar a los consumidores: 1. Ventajas racionales: lo que el producto hace, su función. 2. Ventajas sensoriales: efectos del producto en los sentidos, características físicas, packaging, aspecto, forma, aroma, tacto, sabor, forma de usarlo... 3. Ventajas emocionales: sensaciones o sentimientos que evoca el producto o su marca (Ibíd., 1998, p. 51).

Entonces, desarrollar un trabajo creativo con el uso de las estrategias persuasivas adecuadas requiere de una investigación encaminada a conocer todos los aspectos relacionados con el cliente y con sus móviles de compra: a) el número aproximado de ventas del nuevo producto; b) la inversión necesaria en publicidad; c) los medios más 
adecuados para posicionar el producto; d) las particularidades del destinatario del mensaje; e) los elementos que determinan la compra; f) el vocabulario a utilizar para llamar la atención de los consumidores; g) la "promesa publicitaria" más ventajosa; h) si es acertada la publicidad; i) ¿cuál fue la publicidad televisiva más motivadora?; j) la cantidad de personas que miran la publicidad, la escuchan o la leen y, las que la memorizan.

\subsection{SEDUCIR PARA DOMINAR}

Si bien es cierto que los presupuestos anteriores siguen manteniendo aplicabilidad, no se puede desconocer que la publicidad necesita adaptar sus estrategias a la realidad circundante. Actualmente existen nuevas formas de conocer la opinión del cliente, por medio de encuestas y comunidades online, a través de las redes sociales y de los métodos dispuestos en Internet para observar masivamente a los consumidores o a través de sus teléfonos móviles. "Tenemos nuevas formas de visualizar y analizar datos (en tiempo real, con herramientas mucho más potentes y visuales...) e incluso empezamos a contar con pioneros algoritmos para tratar de predecir el comportamiento del consumidor a partir de ingentes cantidades de información que somos capaces de almacenar" (López, 2017, p. 7). Pero, en esencia la investigación sigue utilizando las herramientas que utilizaba en los años 60 porque la totalidad de los adelantos se han orientado a optimizar la investigación. No obstante, la introducción de las neurociencias en la investigación de mercado sí constituye un cambio radical para ésta y representa una verdadera revolución dentro de las herramientas del mercado. Bernard Stiegler (2008, p. 236) considera que vistas las cosas desde nuestra perspectiva del siglo XXI, la cuestión ya no es, y hoy aún menos lo que en tiempos de Packard (1957), "controlar la población como máquina de producción, sino como máquina de consumo". En consecuencia, lo que Stiegler denomina "psicopoder" es quien controla y fabrica las motivaciones. De este modo, los estudios publicitarios se orientan hacia las investigaciones relacionadas con la mente para vaticinar lo que busca el consumidor. $Y$, "con mucha atención [tomar] nota de los anhelos, las necesidades y los deseos, en lugar de 'desimpregnarlos'. Con la ayuda de pronósticos, se anticipa a las acciones, incluso actúa antes que ellas en lugar de entorpecerlas. La psicopolítica neoliberal es una 
política inteligente que busca agradar en lugar de someter" (Han, 2014, p. 57). Y hacia ahí se orienta el neuromarketing.

Han (2014, p. 71), al hablar sobre el significado de las emociones para el neoliberalismo dice que:

A partir de un determinado nivel de producción, la racionalidad, que representa el medio de la sociedad disciplinaria, topa con sus límites. La racionalidad se percibe como coacción, como obstáculo. De repente tiene efectos rígidos e inflexibles. En su lugar entra en escena la emocionalidad, que corre paralela al sentimiento de libertad, al libre despliegue de la personalidad. Ser libre significa incluso dejar paso libre a las emociones. El capitalismo de la emoción se sirve de la libertad. Se celebra la emoción como una expresión de la subjetividad libre. La técnica de poder neoliberal explota esta subjetividad libre.

Las emociones desempeñan un papel primordial en las decisiones que toman los consumidores cada día; por eso cristalizan como el objetivo hacia al cual la publicidad dirige sus mensajes "como la forma más rápida de influenciar al público" (Feenstra, 2013, p. 15). El experimento llevado a cabo por el científico Read Montague legitima el significado que para el consumidor tiene evocar determinados sentimientos. Ante una marca conocida, la región del cerebro encargada de la reflexión y del raciocinio -el neocórtex-relaja su actividad y baja su nivel de activación. Así ahorra energía y activa la zona de emociones, facilitando la acción instintiva e irreflexiva por parte del consumidor. Entonces, el éxito de la publicidad está determinado en gran medida por su facultad para activar dos de las partes del cerebro: el sistema límbico (que tiene que ver con las emociones) y el cerebro reptiliano (encargado de controlar las conductas instintivas y las necesidades primarias: hambre, deseos sexuales y temperatura corporal) y evitar que el neocórtex (que se encarga del razonamiento abstracto y del lenguaje), impida que se atrase o se evite la compra.

Las últimas investigaciones sobre "inteligencia emocional" prueban que las emociones deben trabajarse para que broten de manera automática del subconsciente porque son la razón fundamental de la existencia de las marcas. Por ejemplo, Álvarez (2011, p. 45) 
explica que: "Marcas como Coca-Cola, Procter\&Gamble, Unilever, Nestlé, Hallmark, Glaxo o Apple, han llevado a cabo profundos análisis sobre emociones específicas para comprender sus matices más sutiles y su funcionamiento" Sobre esta base, define las emociones como "comunicaciones a uno mismo y a los demás que señalan acontecimientos relevantes para las propias necesidades significativas u objetivos" (Álvarez, 2011, p. 46). Y Agrega: "Las vivencias emocionales son cruciales, constituyen el componente central de las decisiones que realizamos. La mayoría de las decisiones importantes involucran complejos intercambios: precio versus seguridad para la compra de un automóvil o riesgos versus progreso al seleccionar la educación de los hijos" (Ibíd.).

Eagleman (2013, p. 132) explica que las diversas partes del cerebro mantienen un diálogo constante, pero cada una apuesta por dominar la única vía de escape hacia el exterior, "que es su comportamiento. Como resultado, puede llevar a cabo las extrañas proezas de discutir consigo mismo, insultarse y engatusarse para hacer algo: proezas que nuestros ordenadores modernos simplemente son incapaces de hacer". Luego indica:

El sistema racional es el que se ocupa del análisis de las cosas del mundo exterior, mientras que el sistema emocional controla los estados internos y se preocupa de si las cosas irán bien o mal. (...) Puede resolver un problema de matemáticas sin consultar con su estado interno, pero no puede pedir un postre en un menú ni priorizar lo que le apetece hacer a continuación. Las redes emocionales son absolutamente necesarias para clasificar las posibles acciones que podría llevar a cabo en el mundo (Eagleman, 2013, p. 136).

El control de las emociones es fruto del dominio que ejerce el entorno social en la multiplicidad del desarrollo del cerebro y, éste a su vez, se convierte en un factor determinante para las decisiones de compra que realiza cada individuo (Eco, 1974, p. 229; Bermejo, 2001; Manes, 2011, p. 15). El contexto físico y simbólico que rodea al ser humano es fundamental para la conformación de su estructura mental, pues su desarrollo, como persona, depende en gran medida de los vínculos que establece con el entorno, en tanto éste influye en su realidad, condiciona su personalidad e interviene 
en su conducta. De ahí la importancia que la publicidad le concede al entorno cultural y al contexto social de las personas para crear el sentido de los mensajes.

\section{EL NEUROMARKETING PARA FABRICAR EMOCIONES}

La llegada del siglo XXI enfrenta a la investigación científica a nuevos retos. Junto al desarrollo de las nuevas tecnologías se produce el avance de la globalización y, ante esta realidad, los estudios desembocan en las neurociencias y, de manera específica, en la aplicación de técnicas de neuromarketing a la investigación de mercado. El neuromarketing puede conceptualizarse como un método de vanguardia, que se ocupa de investigar los procesos que ocurren en el cerebro, con el fin de revelar las causas de una u otra conducta y las decisiones de las personas en los terrenos de la actividad del marketing tradicional: "inteligencia de mercado, diseño de productos y servicios, comunicaciones, precios, branding, posicionamiento, targeting, canales y ventas" (Braidot, 2013, p. 16).

Con el uso de diferentes tipos de tecnologías se "leen" directamente las "respuestas" que el cerebro -de los participantes en pruebas de este tipo-ofrece a los estímulos que se le aplican, que pueden ser: un anuncio, un producto, etc. Ello permite "por ejemplo, averiguar qué nivel de atención están prestando los sujetos estudiados a un anuncio segundo por segundo y plano por plano" (Monge y Fernández, 2011, p. 21). Para realizar estas investigaciones se parte del significado que para los seres humanos tienen las emociones y el intercambio de ellas. De ahí que la tarea de la publicidad sea "incrementar el fenómeno emocional del objetivo deseado a fin de impactar en el proceso de decisión" de los consumidores (Álvarez, 2011, p. 47-48).

Los partidarios del neuromarketing son firmes en la idea de que las pruebas muestran, sin temor a equívocos, que las emociones están por encima de la razón, el hecho de que como seres humanos sintamos y luego razonemos es considerado como algo beneficioso para el marketing, en tanto que el $85 \%$ de las decisiones son tomadas por el cerebro de manera automática sin que medie la reflexión. El neuromarketing aporta una amplia cantidad de recursos para estudiar el mercado, segmentarlo y crear productos eficaces, tanto en cuanto a diseño, a marca y a embalaje se refiere. "Estos recursos se 
basan en el conocimiento de los procesos cerebrales vinculados a la percepción sensorial, el procesamiento de la información, la memoria, la emoción, la atención, el aprendizaje, la racionalidad, las emociones y los mecanismos que interactúan en el aprendizaje y toma de decisiones del cliente" (Braidot, 2013, p. 16). Por ejemplo, Michelin enfoca su comunicación hacia los niños y, con el interés de promover los neumáticos, hace énfasis en la necesidad de proteger a la familia, lo que significa que aparte de la solidez del producto y de su costo, existe un valor adicional que es todavía superior.

Las emociones son las grandes constructoras de la memoria, por eso es comprensible que se recuerde más fácilmente aquello que se relaciona con el afecto. De esta manera, una marca se percibe como más efectiva cuando estimula las zonas del cerebro vinculadas al afecto, al punto de aumentar las posibilidades de selección. Por ejemplo, cuando las personas aprenden que un grupo actúa de una determinada forma, lo distinguen en base a ese modelo y desconocen las formas que no se corresponden con él. Esto no sólo es legítimo para las personas, sino también para los hechos, las mercancías y, también para las marcas comerciales. En este sentido, el neuromarketing aconseja usar modelos humanos para formar impresiones positivas en los clientes que se vinculan a la marca, pues "el tiempo de reacción hacia los rostros felices es más veloz que para las caras negativas, debido a que son menos ambiguas, fenómeno que es conocido como ventaja del rostro feliz. En general, las respuestas a características negativas son más lentas al captar la atención y alterar el comportamiento, particularmente válido en las respuestas a caras con expresiones airadas" (Álvarez, 2011, p. 80).

Las emociones se manifiestan a través de expresiones faciales similares en todas las personas. Y, aunque a las personas les cuesta trabajo identificar cuáles son las emociones básicas, a nivel científico se tiene consenso de que son seis: enojo, miedo, aversión, alegría, tristeza y sorpresa. Éstas se pueden dividir en primarias y secundarias $y$, a su vez, en positivas y negativas. Las primeras se vinculan a experiencias placenteras y significan que la situación a la que se enfrenta el ser humano es favorable y, las segundas, por el contrario, están unidas a experiencias desagradables y son percibidas 
como amenazas, para alcanzar un propósito, por ejemplo (Ostrosky, Chayo, Castillo, Vélez y Arias, 2003, p. 214-215; Casassus, 2006; García, 2012). De la misma forma, una persona puede experimentar diferentes emociones en un solo momento (Santrock, 2002).

Por ejemplo, años atrás, una marca de pizza realizó una investigación para conocer cuál era el miedo de las personas al pedir una pizza a domicilio. El estudio demostró que el temor lo ocasionaba la ansiedad que producía desconocer el tiempo que demoraría la pizza. Con esta valiosa información, Domino's Pizza hizo una eficaz propuesta, cuya campaña le garantizaba al cliente que se le entregaría la pizza en: "Menos de treinta minutos (o es gratis)". Este recurso sólo se podía poner en práctica con una investigación encaminada a conocer la emoción de los consumidores para darle solución al problema.

Con el uso de las técnicas procedentes del neuromarketing se aspira a responder con mayor nivel de exactitud a muchos de los cuestionamientos que se plantean los creativos sobre: los estímulos que han de aparecer en el anuncio para que su impacto sea mayor, las veces que la publicidad ha de repetirse en los diferentes medios, la forma en la que el consumidor ha de ser tratado para que se mantenga por más tiempo en un comercio, compre más y vuelva, los sentidos a los que el producto ha de dirigir los estímulos para que el cliente se sienta complacido, los mecanismos que se deben de implementar en relación al costo y la forma en que el equipo de ventas debe de ser entrenado para ser eficaz. Las consultoras e instituciones especializadas en conocer el funcionamiento del cerebro, cuando aplican las pruebas para conocer el comportamiento de los consumidores, incluyen los diferentes medios con que cuentan, desde encefalogramas hasta otras técnicas encargadas de examinar la acción eléctrica. Incluso, tomografías capaces de administrar neuroimágenes computarizadas (Monge y Fernández, 2011, p. 22-25). Sin embargo, las piezas audiovisuales, al podérseles "aislar como estímulo único", son las que más posibilidades ofrecen a los estudios con técnicas de neuromarketing (Monge y Fernández, 2011, p. 28-29).

Así y todo, la imposibilidad de simular por medio de estas técnicas ambientes complejos como el punto de venta, el diseño de las mercancías, su envase o representar el contexto 
de un hotel en uso había frenado la investigación científica, pero esto está siendo superado gracias a tecnologías basadas en la realidad virtual o en la combinación de la realidad virtual con otras técnicas. Éstas posibilitan evaluar la correspondencia fisiológica y cerebral que se produce cuando el cliente se tele-transporta a uno de estos ambientes. La realidad mixta "puede definirse como un nuevo sistema tecnológico que permite la inserción de contenidos virtuales en el mundo real del usuario para funcionar en la misma representación y en tiempo real" (Alcañiz, Bigné y Guixeres, 2017, p. 7). Por su parte, el empleo de escenarios virtuales "en las gafas es compatible con la medición de eyetracking en el mismo dispositivo (gafas de realidad virtual), a lo que se le suma sincronizadamente medidores biométricos: galvanometría, frecuencia cardíaca y electroencefalografía. Todo ello nos permitirá aportar al estudio información emocional esencial" (Graña 2017, p. 22).

El neuromarketing puede correlacionar las percepciones subjetivas e instintivas con estímulos y conductas de los consumidores a partir del análisis de actividades simultáneas en distintas áreas del cerebro. Básicamente, tendrá mayores argumentos para entender diferentes aspectos paradigmáticos que se vinculan al diseño y estilo de la marca. Por ejemplo:

- Respuesta emocional hacia la marca.

- Elementos estéticos que llaman la atención.

- Emoción del producto.

- Texturas, formas, colores... que generan la mayor conexión emocional.

- Características más recordadas.

- Atributos que más se disfrutan.

- Aspectos de la interrelación 'naturales' e 'intuitivos'.

- Aspectos relacionales que deleitan, atraen. 
- Aspectos estéticos relacionales, con los cuales los clientes se conectan emocionalmente.

- Atributos que se recuerdan con mayor facilidad.

- Estilo de packaging que represente adecuadamente los atributos de la marca.

- Formatos, colores y tratamiento del logo que atrapen la atención y emocionalmente impacte.

- Atributos de la marca y de la publicidad que deben incorporarse al packaging para impactar en la memoria y ser recordada (Álvarez, 2011, p. 80).

Del mismo modo, se tiene en cuenta: 1) qué anuncios de la competencia recuerdan los clientes; 2) la vinculación que hacen con la esencia y sentido de las marcas de la competencia en su publicidad, con el fin de dar respuesta a las necesidades; 3) cualidades y argumentos emocionales afines con las marcas de la competencia o con la propia publicidad, además de hacer hincapié en 4) qué se recuerda de la publicidad de las marcas de la competencia. En lo que respecta al precio, se analiza la reacción no verbal, a nivel cognoscitivo, que se produce a partir de las alianzas de la marca, a través de los niveles de precio, las formas emocionales y perceptibles en que reaccionan los clientes ante el precio, las cuales señalan cuál es el precio más indicado para la marca. Además, se contempla la forma en que se manifiesta el cerebro ante el precio, antes de que se racionalice o se verbalice.

Sin embargo, para entender el vínculo que el cliente mantiene con la marca hay que entrar a cada una de las zonas en las que la memoria guarda la marca (la procedimental, la episódica y la semántica), pues su recuerdo no se almacena de la misma forma que cuando visualizamos una fotografía, una película o un vídeo, sino que se registra como si fuera un programa que moviliza todas las cadenas comunicativas vinculadas a él, por ejemplo, los sonidos, las palabras, las imágenes conmovedoras, la representación de las cosas en nuestra mente y los sentimientos. Es decir, que lo que la persona recuerda se 
reconstruye en relación a lo que ha aprendido y ejercitado, que se vincula con elementos de su presente.

Davis (2002, p. 21) afirma que los aspectos que mantienen la fidelidad de los clientes a una marca son los siguientes: "La marca ofrece una gran calidad (70\%); tiene un desempeño consistente (61\%); es la que conocen (33\%); representa una buena relación precio/valor (30\%); se ajusta bien a la personalidad (26\%); resuelve eficazmente el problema (26\%)". Asimismo, aconseja que:

[...] para armar una imagen de marca es necesario en primer lugar desarrollar una comprensión plena de la imagen de su marca en la mente de los clientes pasados, presentes y futuros. Como una persona, su marca puede describirse con adjetivos, adverbios y frases. Entre más positivos sean, más fuerte será la imagen de su marca y usted tendrá mayor capacidad de apalancar el crecimiento de la misma.

Con una tónica similar, Salmon (2008) explica que en la valoración de las marcas ha prevalecido el carácter histórico, pues, tal como demuestran los hechos, cuando los seguidores de una marca han comprobado que bajo su símbolo se encubre la explotación, la han reprochado y/o abandonado. Igualmente, Álvarez (2011) argumenta que la formación de asociaciones es determinante para que se desarrolle la identidad de marca. Por eso, las marcas que tienen una fuerte participación en el mercado, tienen grandes y claras asociaciones que están activadas en las zonas del cerebro, cuyo poder lo ejerce la recompensa, el llamado centro universal de la motivación o estriado ventral. Su representación tiene lugar a partir de asociaciones del significado de los signos lingüísticos y visuales, aunque son estos últimos los que tienen el papel de mayor preponderancia. De ahí que la relación con la marca sea mayor cuantas más experiencias el cliente haya tenido con ella, mayor haya sido su exposición a la publicidad y mayor la red de vínculos que lo unan a ella.

Para comunicarse con su target, las marcas se enfocan en los canales básicos que usa el cerebro para el aprendizaje: el visual, el auditivo y el cinestésico. Los estudios evidencian que su desarrollo se produce de manera desigual en todos los seres humanos: el $40 \%$ de las personas se vale del canal visual para aprender, pero sólo el $20 \%$ es 
fundamentalmente auditivo y el otro $40 \%$ es cinestésico. "A nivel neurológico el éxito es mucho más informativo que el fracaso. Por eso, cuando se obtiene una recompensa, el cerebro recuerda lo que ha hecho bien. Pero si es un fracaso (excepto que tenga claras consecuencias negativas) el cerebro no está seguro de lo que almacenar, por lo que no sufre cambios" (Álvarez, 2011, p. 57). Esto explica por qué la publicidad es "afirmativa" o sólo en raras ocasiones recurre al fracaso. En este sentido, el autor explica que las investigaciones evidencian que los consumidores, aunque entre unos y otros mantienen diferencias y semejanzas, todos "comparten el mismo modo de aprender, pensar y sentir sobre un mismo tema. Estas similitudes impulsan el aprendizaje del consumidor con gran fuerza y permanecen sorprendentemente estables en el tiempo" (Ibíd.).

Las asociaciones pueden ser variadas, como también las formas en que pueden aportarle prestigio, tanto a la empresa como a los clientes. Por ejemplo, para una pizzería tener un nombre italiano le reporta valor, pero, si además, el chef es italiano y tiene diferentes elementos que la vinculan a Italia, merecerá mayor respeto por parte del público, sin importar en qué lugar del mundo esté ubicada. Esto mismo ocurrirá con una tienda especializada en quesos y vinos franceses, por ejemplo. Al establecer asociaciones en entornos apropiados se producen estímulos agradables que le impiden al consumidor emitir argumentos negativos en su contra y, a la vez despiertan su interés, pero no sólo eso, sino que se trasladan a la marca. Tales son los casos de la simpatía que le transfiere George Clooney a Nesspreso o Rafa Nadal a la marca KIA.

La calidad que el consumidor percibe sobre la marca está estrechamente vinculada con una visión abstracta y difiere de la calidad objetiva. Más que nada es una noción global que en casos particulares puede asemejarse a posturas y a un criterio formado casi en su totalidad desde el conjunto recordado por el cliente. En muchos entornos la calidad que el consumidor percibe se convierte en la asociación más trascendente para el significado de la marca y vincula a la marca con un precio superior, con la moda y con un cierto prestigio. Pero también se manifiesta en una estrecha relación con valores específicos que la identifican y que comprenden características particulares sobre sus utilidades prácticas. Por ejemplo, los altavoces de cadenas de sonido: cuanto mayor sea 
el tamaño, se considera que la calidad del sonido es mejor. Asimismo, en el caso de los detergentes, más espuma es sinónimo de mejor efecto en el lavado.

\subsection{NEUROMARKETING Y SATISFACCIÓN DE NECESIDADES}

El neuromarketing apunta a satisfacer las necesidades humanas presentes en los tres niveles del cerebro, "y en la posterior conversión de éstas en deseos y demanda" (Braidot, 2013, p. 25). De ahí que la compra de mercancías y servicios que tienen que ver con la seguridad aumenta cuando hay un sentimiento de inseguridad, que "tiene su base en el cerebro reptiliano, que es instintivo" (Ibíd.). Conocer la especialización hemisférica del cerebro le permite al neuromarketing segmentar el mercado para diseñar estrategias de marketing adecuadas. Por ejemplo, ante las novedades, existe mayor posibilidad de captar a los clientes en los que predomina el pensamiento propio del hemisferio cerebral derecho, que son los primeros en acogerse a las novedades. De tal manera que, cuando los mensajes publicitarios subrayan "aspectos emocionales, capitalizan esas diferencias entre hemisferios. Cuando se logra impresionar al derecho, se evita que la actitud racional y crítica del izquierdo pase a un primer plano. Esta misma estrategia es utilizada en los puntos de venta, cuando lo que se busca es desencadenar la compra por impulso" (Braidot, 2013, p. 32). No obstante, para disminuir la sensación que puede ocasionar el precio se aconsejan imágenes y conceptos relativos a la amistad, a la belleza y al amor, que impacten al hemisferio derecho e impidan las reacciones del izquierdo, sensible a los cálculos.

Los seres humanos representamos el mundo a través de nuestras percepciones externas e internas. Por eso, la percepción influye no sólo en el posicionamiento de las mercancías, sino también en la actitud del cliente hacia ellas y en su recuerdo. De ahí que un producto se pueda definir como "una construcción cerebral" (Braidot, 2013, p. 34), que depende tanto de factores externos como de factores internos (entre los que se encuentran las cualidades físicas de la mercancía, el precio y la publicidad, como las experiencias del cliente, su personalidad, su historia, valores y modo de vida). Por eso las expresiones metaconscientes relacionadas con la percepción son tan importantes en las decisiones del consumidor, pues los deseos, en su gran mayoría, están determinados 
por el modo en que los seres humanos interiorizan los elementos culturales y sociales. Entonces, tanto la memoria emocional como la episódica guardan vínculos con ciertos productos y servicios y también con las marcas que los amparan.

Los estudios de neuromarketing permiten descubrir qué aspectos son capaces de poner en acción los sistemas de recompensa cerebral, para diseñar estrategias basadas en la satisfacción del placer con el propósito de atraer a los consumidores hacia la marca de interés publicitario. En este sentido, se ha comprobado que existe una correspondencia entre la importancia que se le concede a la compra y la implicación de la "memoria del metaconsciente" o "conjunto de experiencias, sentimientos y emociones que vamos incorporando a lo largo de la vida que determinan no sólo nuestra particular construcción de la realidad, sino también las decisiones que tomamos como consumidores" (Braidot, 2013, p. 50).

Las necesidades básicas se relacionan con la sensación de carencia o con la ausencia de algo, pero no están unidas a una marca en particular. Sin embargo, las necesidades "derivadas" sí tienen una relación directa con las marcas o "con lo que el cliente percibe que resuelve la insatisfacción o carencia que experimenta en forma específica, por lo tanto, las estrategias de las empresas se dirigen hacia ellas" (Ibíd). Estos dos tipos de necesidades están ubicadas en zonas diferentes del cerebro, pero, como las marcas se han encargado de construir imágenes relativas a la marca, éstas nos llevan a asociar las necesidades genéricas con aspectos específicos de las necesidades derivadas. Por ejemplo, la marca de agua Evian nos llevaría a pensar en frescura y naturaleza, de la misma forma que la cerveza Presidente nos transmite el deseo de compartir con la familia y con amigos, mientras disfrutamos de la playa o de la naturaleza dominicanas. Las necesidades básicas siempre existen, de ahí que son las encargadas de precisar en qué negocio la empresa habrá de operar. Sin embargo, las derivadas no son constantes, pero están conectadas a los deseos, hecho que las convierte en un reto para "diseñar productos y servicios que suministren los mejores satisfactores y lo hagan en forma diferenciada" (Braidot, 2013, p. 51). 
Álvarez (2011, p. 42), al referirse a este tema indica que si se entiende "el espectro de los sentimientos y emociones se pueden provocar experiencias estimulantes e inolvidables", pues, por ejemplo, "el color oro otorga mayor prestigio a los objetos que envuelve". El verde "provoca sensaciones de naturaleza; el azul de frescor". Asimismo, "el olor a madera provoca sensaciones de masculinidad; el floral sugiere feminismo", etc. Tal es el significado de las emociones, que hay especialistas que trabajan en diferentes establecimientos para hacer que crezca la satisfacción y el bienestar de los consumidores, con el propósito de que permanezcan por mayor tiempo en el lugar, vuelvan o lo recuerden y regresen. (Ibíd.).

El producto de marca está asociado a varios factores de naturaleza psicosocial. Eso explica por qué muchos consumidores consideran que la adquisición del objeto les genera seguridad, estatus y un supuesto prestigio, a la vez que les garantiza disfrutar de una hipotética calidad de vida. De manera que, como los autos deportivos, "simbolizan la velocidad, el poder y la independencia e indican abundancia y superioridad [que es] una fuerte señal de dominación social" (Braidot, 2013, p. 54). En circunstancias de mercado, una mercancía que se vincule a los autos deportivos es capaz de activar las mismas áreas del cerebro que se relacionan con la recompensa.

El neuromarketing parte de la premisa de que los clientes no se comportan tan racionalmente como afirmaba la economía clásica, pues se ha comprobado que eso sólo ocurre cuando se compran objetos con significado funcional. En una promoción de vinos realizada por Plassmann y colaboradores, encaminada a conocer la influencia que algunas acciones de marketing podían tener en la excitación neuronal de los consumidores, se pudo comprobar que en la medida en que el precio del vino aumentaba, mayor era la acción neuronal relacionada con el placer y con la recompensa, pero, al mismo tiempo, mayor la satisfacción experimentada.

\section{CONCLUSIÓN}

A lo largo de estas páginas hemos podido explicitar que el desarrollo de la publicidad en el siglo XX está indisolublemente ligado a la investigación científica, pues la rentabilidad de las empresas en mayor cuando se produce lo que el consumidor desea. El desarrollo 
del mercado, la masificación del consumo y el crecimiento de la competencia se convierten en el motor para el avance de la investigación científica y, a la vez, para que se desarrolle la publicidad. En este sentido, el interés de los profesionales del marketing por conocer la conducta de los consumidores fue un acicate para la aplicación de estrategias innovadoras.

A través de la publicidad, la sociedad moderna no sólo dirige la producción, sino que proyecta y planifica la demanda, pues los publicistas crean necesidades que se corresponden con los productos que ofrece el mercado, aunque sus habilidades hacen creer a los consumidores que compran por sus propios instintos y con total autonomía. Asimismo, el desarrollo de la competencia y la creación de productos semejantes contribuye al desarrollo de las marcas, pues se hace necesario que las mercancías adquieran un nuevo valor y vender símbolos en lugar de productos.

Si bien la investigación científica aplicada al mercado ha experimentado un amplio desarrollo, la gran mayoría de los avances han estado orientados a optimizar la investigación. De manera que son las neurociencias y de manera particular la aplicación de técnicas provenientes del neuromarketing las que están revolucionando la investigación de mercado y los modos de hacer publicidad. Ha entrado en escena la emocionalidad, que, como bien apunta Han (2014) "corre paralela al sentimiento de libertad, al libre despliegue de la personalidad". De modo que la publicidad, al conocer cuáles son los mecanismos que ponen en acción los sistemas de recompensa cerebral, diseña estrategias basadas en la satisfacción del placer para atraer a los consumidores hacia el producto publicitado.

\section{REFERENCIAS BIBLIOGRÁFICAS}

Alcañiz, M., Bigné, E. y Guixeres, J. (2017). Neuromarketing: midiendo en realidad y en realidad mixta. Investigación y Marketing, 134, Marzo, 6-9.

Álvarez, R. (2011). Neuromarketing, Fusión Perfecta. Seducir al cerebro con inteligencia para ganar en tiempos exigentes. Madrid: Pearson Educación.

Bassat, L. (1998). El Libro Rojo de la Publicidad. Madrid: Espasa Calpe. 
Bermejo, J. (1998). El receptor en la Psicología: Del sujeto epistémico al sujeto biopsicosociocultural. Publifilia. Revista de Culturas Publicitarias, 1, 51-65.

Braidot, N. (2013). Neuromarketing. ¿Por qué tus clientes se acuestan con otro si dicen que les gustas tú? Barcelona: Gestión 2000.

Casassus, J. (2006). La educación del ser emocional. (1a ed.). Universidad Virtual del Instituto Tecnológico de Monterrey. Monterrey: Ediciones Castillo.

Correyero, B., Machado, B. y Baladrón, A. J. (2018). Evolución histórica de la investigación publicitaria en España: de los orígenes científicos de la publicidad al actual auge investigador. AdComunica Revista científica de estrategias, tendencias $e$ innovación en comunicación, 15, 89-113. DOI: http://dx.doi.org/10.6035/2174$\underline{0992.2018 .15 .6}$

Davis, S. M. (2002). LA MARCA, máximo valor de su empresa. México D.F.: Pearson Educación.

Dostoievski, F. (1980). El jugador. Madrid: Alianza Editorial.

Eagleman, D. (2013). Incógnito. Las vidas secretas del cerebro. Barcelona: Anagrama.

Eco, U. (1974). La estructura ausente. Introducción a la semiótica. Barcelona: Lumen.

Eguizábal, R. (2006): «Del consumo de élite al consumo de masas». En Martín Requero, M. I. y Alvarado López, M. C. (coords.) Publicidad y cultura: La publicidad como homologdor cultural (pp. 62-93). Sevilla: Comunicación Social Ediciones y Publicaciones.

Feenstra, R. (2013). La irrupción de la neuropublicidad y sus debates éticos. Daimon Revista Internacional de Filosofía, 59, 45- 56.

García, J. A. (2012). La educación emocional, su importancia en el proceso de aprendizaje». Revista Educación, 36(1), 1-24.

Graña, J. (2017). Realidad virtual: la nueva dimensión para el futuro del neuromarketing. Investigación y Marketing, 134, 20-23. 
Han, B. C. (2014). Psicopolítica. Neoliberalismo y nuevas técnicas de poder. Barcelona: Herder.

Laqueur, W. (1985). Europa después de Hitler. Vol. I y II. Madrid: Sarpe.

León, J. L. (1992). Ciencia y acción de marketing. Investigación y Marketing, marzo, 4452.

Lipovetsky, G. (1990). El imperio de lo efímero. La moda y su destino en las sociedades modernas. Barcelona: Anagrama.

López, M. (2017). ¿Cómo afectará la cuarta revolución industrial al sector de la investigación de mercados? Investigación y Marketing, 136, 6-10.

Manes, F. (2011). Prefacio. En Álvarez del Blanco, R. Neuromarketing, Fusión Perfecta. Seducir al cerebro con inteligencia para ganar en tiempos exigentes (pp. 15-17). Madrid: Pearson Educación.

Monge, S. y Fernández, V. (2011). Neuromarketing: Tecnologías, Mercado y Retos. Pensar la Publicidad, 5(2), 19-42.

Ostrosky, F., Chayo, R., Castillo, G., Vélez, A. E. y Arias, N. (2003). Valencia, activación, dominancia y contenido moral, ante estímulos visuales con contenido emocional y moral: Un estudio en población mexicana. Revista Española de Neuropsicología, 5(3-4), 213-225.

Packard, V. (1957). The Hidden Persuaders. New York: McKay.

Rothenberg, R. (1999). The advertising century. Advertising Age: Special Issue.

Russell, T. J., Lane, W. R. y Whitehill, K. (2005). Publicidad, México D.F.: Pearson Educación.

Santrock, J. (2002). Psicología de la Educación. México D.F.: McGraw-Hill.

Salmon, C. (2008): Storytelling: La máquina de fabricar historias y formatear las mentes. Barcelona: Península. 
Winer, R. S. (2011): Prólogo. En Álvarez del Blanco, R. Neuromarketing, Fusión Perfecta. Seducir al cerebro con inteligencia para ganar en tiempos exigentes (pp. 11-15). Madrid: Pearson Educación.

Zymana, S. (1999): El final del marketing que conocemos. Barcelona: Granica. 